\title{
Một số ấn phẩm tiêu biểu mới xuất bản của Nhà xuất bản Chính trị quốc gia Sự thật
}

\author{
NGUYỄN CHẮT \\ Nhà xuất bản Chính trị quốc gia Sự thật \\ Chính trị và Phát triển
}

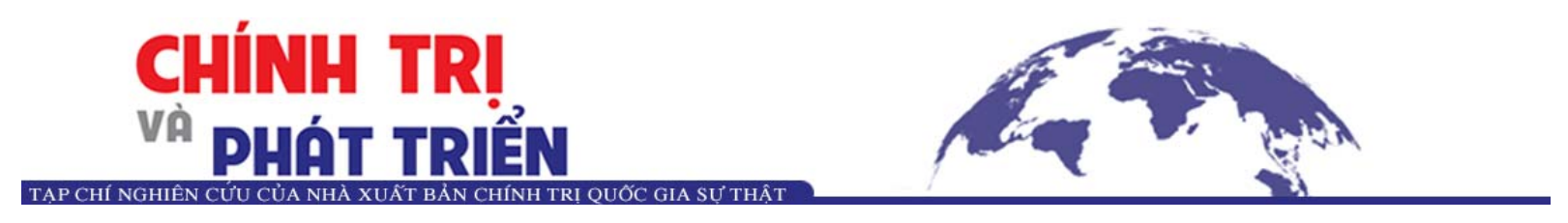

Ngày 16 tháng 09 năm 2021

http://www.chinhtrivaphattrien.vn/Detail.aspx?id=1412 


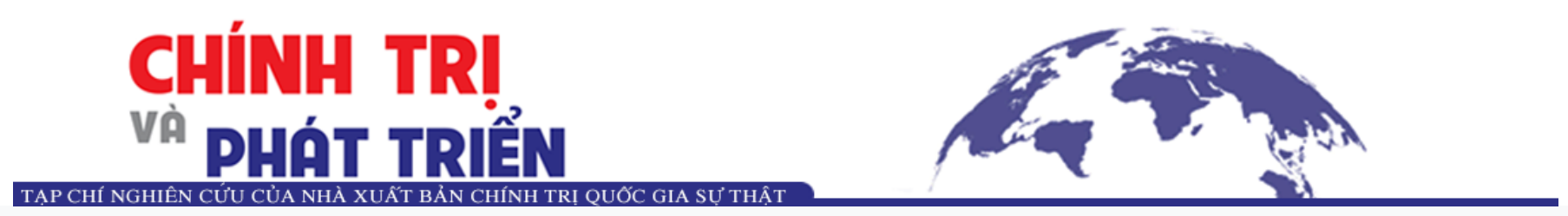

Thứ năm, 16/09/2021 13:11:27 (GTM +7)

\section{Một số ấn phẩm tiêu biểu mới xuất bản của Nhà xuất bản Chính trị quốc gia Sự thật}

CT\&PT - Nhà xuất bản Chính trị quốc gia Sự thật là cơ quan xuất bản sách lý luận, chính trị, pháp luật và tư tưởng Hồ Chí Minh của Đảng và Nhà nước. Để thực hiện tốt vai trò của mình, trong nhiều năm qua, Nhà xuất bản đã đẩy mạnh công tác phối hợp với các cơ quan, ban, bộ, ngành Trung ương và địa phương, tổ chức biên tập, xuất bản và phát hành hàng nghìn đầu sách với các mảng đề tài phong phú. Gần đây, Nhà xuất bản tập trung biên tập và xuất bản mảng sách trọng tâm về: bảo vệ nền tảng tư tưởng của Đảng; phục vụ Đại hội đại biểu toàn quốc lần thứ XIII của Đảng; phục vụ cuộc bầu cử đại biểu Quốc hội khóa XV và đại biểu Hội đồng nhân dân các cấp nhiệm kỳ 2016-2021; bộ giáo trình phục vụ công tác nghiên cứu, giảng dạy và học tập; tiểu sử các đồng chí lãnh đạo chủ chốt, tiêu biểu của Đảng và cách mạng Việt Nam; bảo vệ chủ quyền biên giới, hải đảo của Tổ quốc; sách về công tác tuyên truyền, thông tin đối ngoại; sách phổ biến, tuyên truyền, giáo dục pháp luật, v.v.. Tạp chí Chính trị và Phát triển trân trọng giới thiệu tới bạn đọc một số ấn phẩm có ý nghĩa lý luận và thực tiễn sâu sắc được Nhà xuất bản Chính trị quốc gia Sự thật ấn hành trong thời gian qua.

\section{Sách bảo vệ nền tảng tư tưởng của Đảng}

Để nâng cao hiệu quả nhiệm vụ chính trị, nhằm phản bác quan điểm sai trái của các thế lực phản động, thù địch, góp phần bảo vệ và phát triển lý luận chủ nghĩa Mác - Lênin, tư tưởng Hồ Chí Minh, kiên định con đường xã hội chủ nghĩa; giữ vững và tăng cường sự lãnh đạo của Đảng, Nhà nước, nâng cao ý thức cách mạng trong cán bộ, đảng viên và nhân dân, Nhà xuất bản luôn chú trọng đầu tư vào mảng đề tài sách bảo vệ nền tảng tư tưởng của Đảng. Tiêu biểu như:

Cuốn sách Tầm nhin chiến lược và ý chí vươn lên của dân tộc (Báo Nhân dân tuyển chọn) là cuốn sách có giá trị tư tưởng và chỉ đạo thực tiễn sâu sắc, tập hợp ba bài viết của Tổng Bí thư, Chủ tịch nước Nguyễn Phú Trọng về công tác chuẩn bị, tổ chức, tiến hành đại hội đảng bộ các cấp tiến tới Đại hội đại biểu toàn quốc lần thứ XIII của Đảng, cung cấp quan điểm, tư tưởng chỉ đạo và cách nhìn mới sâu sắc, đầy tâm huyết của người đứng đầu Đảng và Nhà nước; đồng thời, chọn lọc một số bài viết, ý kiến của các nhà nghiên cứu, cán bộ lãnh đạo, quản lý và bạn đọc trên cả nước, tập trung phân tích làm rõ cũng như bày tỏ sự đồng tình, đánh giá cao giá trị tư tưởng được thể hiện trong các bài viết của Tổng Bí thư, Chủ tịch nước. Cuốn sách là tài liệu quý, góp phần truyền tải kịp thời chủ trương, đường lối của Đảng đến cán bộ, đảng viên, giúp các đại biểu dự Đại hội đại biểu toàn quốc lần thứ XIII thấy rõ hơn trách nhiệm, nghĩa vụ thiêng liêng của mình khi được vinh dự tham gia quyết định những vấn đề hệ trọng của đất nước, góp phần vào thành công của Đại hội đại biểu toàn quốc lần thứ XIII của Đảng.

Nhằm góp phần đẩy mạnh học tập, làm theo tư tưởng, đạo đức, phong cách Hồ Chí Minh và gìn giữ những di sản tinh thần của Người, Nhà xuất bản Chính trị quốc gia Sự thật ra mắt cuốn sách Tổng tập chuyên đề Học tập và làm theo tư tưởng, đạo đức, phong cách Hồ Chí Minh do Ban Tuyên giáo Trung ương Đảng biên soạn. Cuốn sách hệ thống các văn bản chỉ đạo của Đảng về học tập và làm theo tư tưởng, đạo đức, phong cách Hồ Chí Minh (2003-2021); nội dung các chuyên đề, chủ đề học tập và làm theo tư tưởng, đạo đức, phong cách Hồ Chí Minh (2003-2020). Cùng với đó, cuốn sách Học tập và làm theo tư tưởng, đạo đức, phong cách Hồ Chí Minh: Hiện thực hóa khát vọng phát triển Việt Nam phồn vinh, hạnh phúc, tập hợp hơn 100 bài phát biểu, bài viết của các đồng chí lãnh đạo Đảng, Nhà nước, các cơ quan, ban, bộ, ngành Trung ương và địa phương, các nhà nghiên cứu, làm rõ những nội dung cơ bản trong tư tưởng Hồ Chí Minh và vai trò, ý nghĩa của tư tưởng Hồ Chí Minh đối với công cuộc đổi mới, xây dựng và bảo vệ Tổ quốc; những kết quả đạt được trong học tập và làm theo tấm gương của Người; từ đó, đưa ra các những giải pháp nhằm tiếp tục đẩy mạnh và nâng cao hơn nữa hiệu quả học tập và làm theo tư tưởng, đạo đức, phong cách Hồ Chí Minh trong giai đoạn mới.Đây là tài liệu có giá trị, giúp cán bộ, đảng viên và nhân dân hệ thống, khái quát những nội dung cơ bản trong tư tưởng, đạo đức, phong cách của Bác; trên cơ sở đó, chủ động học tập và làm theo bằng những việc làm thiết thực, hiệu quả, để việc học tập và làm theo tư tưởng, đạo đức, phong cách Hồ Chí Minh tiếp tục đi vào chiều sâu, trở thành nhiệm vụ thường xuyên của mỗi cấp ủy, tổ chức đảng và cán bộ, đảng viên. Không ngừng tu dưỡng, rèn luyện theo Người đã, đang và luôn là tiêu chí, thước đo, phương châm hành động của mỗi cán bộ, đảng viên; là động lực, cội nguồn sức mạnh để toàn Đảng, toàn dân nỗ lực vượt qua khó khăn, thách thức, đáp ứng yêu cầu cách mạng trong giai đoạn mới. Đặc biệt, trong bối cảnh toàn dân thực hiện Kết luận số 01-KL/TW, ngày 18/5/2021 của Bộ Chính trị khóa XIII về tiếp tục thực hiện Chỉ thị số 05-CT/TW Về đẩy mạnh học tập và làm theo tư tưởng, đạo đức, phong cách Hồ Chí Minh thì những cuốn sách trên càng có ý nghĩa, giúp cán bộ, đảng viên và nhân dân nắm vững, thấm nhuần những lời dạy của Bác; từ đó, có những giải pháp, việc làm cụ thể, thiết thực học tập và làm theo tư tưởng, đạo đức Hồ Chí Minh.

2. Sách phục vụ Đại hội đại biểu toàn quốc lần thứ XIII của Đảng và phục vụ bầu cử đại biểu Quốc hội khóa XV và đại biểu Hội đồng nhân dân các cấp nhiệm kỳ 2016-2021

Đại hội đại biểu toàn quốc lần thứ XIII của Đảng, bầu cử đại biểu Quốc hội khóa XV và đại biểu Hội đồng nhân dân các cấp nhiệm kỳ 2016-2021 là những sự kiện có ý nghĩa trọng đại của đất nước. Nhằm cung cấp thêm tài liệu, góp phần định hướng các cấp ủy Đảng và nhân dân nắm vững và triển khai thực hiện tốt công tác chuẩn bị cho Đại hội và cuộc bầu cử; đồng thời, giúp cán bộ, đảng viên và nhân dân hiểu rõ mục tiêu mà Đại hội đề ra nhằm xác định phương hướng, nhiệm vụ và giải pháp để xây dựng và phát triển đất nước, Nhà xuất bản Chính trị quốc gia Sự thật đã chủ động, nỗ lực, khẩn trương $\uparrow$ bản nhiều ấn phẩm quan trọng nhu: Văn kiện Đại hội đại biểu toàn quốc lần thứ XIII (2 tập); Tài liệu học tập, nghiên cứu, quán triệt và tuyên truyền ${ }^{\prime}$ 
quyết Đại hội đại biểu toàn quốc lần thứ XIII, gồm 03 cuốn: Tài liệu học tập các văn kiện Đại hội đại biểu toàn quốc lần thứ XIII của Đảng (Dùng cho cán bộ, đảng viên ở cơ sở); Tài liệu hỏi - đáp về các văn kiện Đại hội đại biểu toàn quốc lần thứ XIII của Đảng (Dùng cho đoàn viên, hội viên các tổ chức chính trị - xã hội và tuyên truyền trong nhân dân); Tài liệu nghiên cứu các văn kiện Đại hội đại biểu toàn quốc lần thứ XIII của Đảng (Dùng cho cán bộ chủ chốt và báo cáo viên); Những điểm mới trong các văn kiện Đại hội XIII của Đảng; Các văn bản chỉ đạo, hướng dẫn bầu cử đại biểu Quốc hội khóa XV và đại biểu Hội đồng nhân dân các cấp nhiệm kỳ 2021-2026; Công tác bầu cử đại biểu Quốc hội khóa XV, đại biểu Hội đồng nhân dân các cấp nhiệm kỳ 2021-2026 của Mặt trận Tổ quốc Việt Nam; Kiến thức và kỹ năng cơ bản dành cho đại biểu Hội đồng nhân dân các cấp. Ngoài các ấn phẩm tiêu biểu trên, Nhà xuất bản Chính trị quốc gia Sự thật còn xuất bản, phát hành nhiều tài liệu nhằm phục vụ kịp thời nhu cầu nghiên cứu, tìm hiểu của độc giả về các quy định pháp luật về bầu cử đại biểu Quốc hội và đại biểu Hội đồng nhân dân các cấp một cách đầy đủ, chính thống nhu: Hiến pháp nước Cộng hòa xã hội chủ nghĩa Việt Nam; Luật Bầu cử đại biểu Quốc hội và đại biểu Hội đồng nhân dân; Luật Tổ chức chính quyền địa phương; Luật Tổ chức Quốc hội; 200 câu hỏi - đáp về bầu cử đại biểu Quốc hội khóa XV và đại biểu Hội đồng nhân dân các cấp nhiệm kỳ 2021-2026; v.v..

\section{Giáo trình lý luận chính trị dành cho bậc đại học}

Nhằm cung cấp tài liệu giảng dạy, học tập cho giảng viên, sinh viên các trường đại học theo chương trình mới, Nhà xuất bản Chính trị quốc gia Sự thật phối hợp với Bộ Giáo dục và Đào tạo biên soạn, biên tập, xuất bản bộ giáo trình lý luận chính trị gồm 10 cuốn giáo trình dành cho bậc đại học hệ chuyên và không chuyên lý luận chính trị. Bộ giáo trình được tổ chức biên soạn theo chỉ đạo của Ban Tuyên giáo Trung ương Đảng, Bộ Giáo dục và Đào tạo. Công tác biên soạn được thực hiện nghiêm túc, công phu, cẩn trọng, phân định rõ nội dung của từng đối tượng học, từng cấp học, bậc học. Bộ giáo trình lý luận chính trị dành cho bậc đại học hệ chuyên và không chuyên lý luận chính trị gồm 5 môn: Triết học Mác - Lênin; Kinh tế chính trị Mác - Lênin; Chủ nghĩa xã hội khoa học; Tư tưởng Hồ Chí Minh; Lịch sử Đảng Cộng sản Việt Nam.

Các cuốn giáo trình được biên soạn theo tinh thần đổi mới cả về nội dung và phương pháp giảng dạy, tiếp cận với những phương pháp giáo dục mới, cập nhật những nghiên cứu, kiến thức lý luận chính trị mới, chú trọng liên hệ với thực tiễn công cuộc đổi mới, phát triển đất nước, nhất là những thành tựu của 35 năm đổi mới đất nước. Trong đó, các cuốn giáo trình dành cho bậc đại học hệ không chuyên lý luận chính trị cung cấp các vấn đề cơ bản nhất về chủ nghĩa Mác - Lênin, trọng tâm là về chủ nghĩa duy vật biện chứng, chủ nghĩa duy vật lịch sử, gắn với tư tưởng Hồ Chí Minh và đường lối, chủ trương của Đảng. Còn các giáo trình dành cho bậc đại học hệ chuyên lý luận chính trị được các tác giả hệ thống hóa kiến thức theo hướng sâu rộng hơn, đầy đủ hơn, phong phú hơn, cung cấp nhiều kiến thức mới để mở rộng hiểu biết về những vấn đề lý luận, có thêm nhiều nội dung gắn với thực tiễn mở ra nhiều hướng nghiên cứu mới cho người học.

\section{Sách tiểu sử các đồng chí lãnh đạo chủ chốt của Đảng và cách mạng Việt Nam}

Trong năm 2021, Nhà xuất bản Chính trị quốc gia Sự thật đã tổ chức biên tập, xuất bản và tái bản một số cuốn tiểu sử các đồng chí lãnh đạo của Đảng và cách mạng Việt Nam: Lê Văn Lương - Tiểu sử, Tô Hiệu - Tiểu sử, Văn Tiến Dũng - Tiểu sử, Lê Đức Thọ - Tiểu sử, Lương Khánh Thiện - Tiểu sử, Nguyễn Chí Thanh - Tiểu sử, Chu Huy Mân - Tiểu sử; Nguyễn Thị Minh Khai - Tiểu sử;...

Nội dung các cuốn sách trình bày khái quát thân thế, sự nghiệp cách mạng và những đóng góp, cống hiến của các đồng chí lãnh đạo chủ chốt, lãnh đạo tiền bối tiêu biểu của Đảng và Nhà nước đối với dân tộc. Qua đó, góp phần cung cấp nguồn tư liệu lịch sử quý giá phục vụ công tác nghiên cứu, đóng góp thiết thực vào công tác giáo dục chính trị, tư tưởng cho cán bộ, đảng viên và các tầng lớp nhân dân.

\section{Một số tác phẩm có giá trị nghiên cứu chuyên sâu}

Bên cạnh các chủ đề trên, Nhà xuất bản cũng giới thiệu một số tác phẩm có giá trị nghiên cứu chuyên sâu, có ý nghĩa về mặt lý luận và thực tiễn nhu: Lịch sử Đảng Cộng sản Việt Nam (Xuất bản lần thứ hai) (2 quyển); Hỏi - đáp về kết quả 10 năm thực hiện Cương lĩnh xây dụnng đất nước trong thời kỳ quá độ lên chủ nghĩa xã hội (bổ sung, phát triển năm 2011); Kinh tế biển xanh: Các vấn đề và cách tiếp cận cho Việt Nam; Niên giám khoa học năm 2020 (4 tập),... Đây là những đầu sách quý, cung cấp cho các nhà nghiên cứu, bạn đọc những thông tin, tri thức phong phú và có giá trị cao về chính trị, lịch sử, văn hóa.

Đặc biệt, nhằm cung cấp cho bạn đọc thêm tư liệu nghiên cứu, tìm hiểu sâu sắc hơn về nền tảng tư tưởng của Đảng, lịch sử và truyền thống cách mạng Việt Nam và một số vấn đề lý luận căn cốt trong sự nghiệp đổi mới, hội nhập và phát triển đất nước, Nhà xuất bản Chính trị quốc gia Sự thật xuất bản cuốn sách Tư tưởng, lý luận với đổi mới và phát triển đất nước của GS, TS. Nguyễn Xuân Thắng, Ủy viên Bộ Chính trị, Chủ tịch Hội đồng Lý luận Trung ương, Giám đốc Học viện Chính trị quốc gia Hồ Chí Minh.

Cuốn sách tập hợp các bài phát biểu của tác giả tại các hội thảo khoa học cùng các bài viết đã được đăng trên các báo, tạp chí, sách... trong thời gian từ năm 2016 đến nay, được kết cấu gồm 3 phần: Phần thứ nhất: Vững vàng trên nền tảng tư tưởng của Đảng; Phần thứ hai: Bản hùng ca của dân tộc và phát huy truyền thống lịch sử, văn hóa và cách mạng dưới sự lãnh đạo của Đảng; Phần thứ ba: Cơ đồ dân tộc, khát vọng và tầm nhìn phát triển đất nước. Cuốn sách là tài liệu quý, có giá trị khoa học và giáo dục, giúp các cấp ủy, tổ chức đảng các cấp quán triệt sâu sắc hơn về nền tảng tư tưởng, quan điểm chỉ đạo, nhận thức và tư duy lý luận của Đảng ta, chính sách pháp luật của nhà nước và đạo đức cách mạng, tinh thần trách nhiệm của cán bộ, đảng viên và nhân dân, nhất là thế hệ trẻ trong sự nghiệp xây dựng và bảo vệ Tổ quốc, phấn đấu vì một nước Việt Nam xã hội chủ nghĩa, phồn vinh, hạnh phúc, cùng tiến bước, sánh vai với các cường quốc năm châu, thực hiện thành công tâm nguyện của Chủ tịch Hồ Chí Minh vĩ đại và ước vọng của toàn dân tộc ta.

Bên cạnh đó, đáp ứng nhu cầu của đông đảo bạn đọc, Nhà xuất bản Chính trị quốc gia Sự thật đã xuất bản lần thứ hai cuốn sách Kinh tế Việt Nam: Thăng trầm và Đột phá của tác giả Phạm Minh Chính và Vương Quân Hoàng. Cuốn sách được xuất bản lần đầu vào năm 2009, đến nay đã được 10 năm. Đây là một trong những cuốn sách đầu tiên viết về lịch sử kinh tế Việt Nam sử dụng cách tiếp cận mới, áp dụng nhiều công cụ phân tích kinh tế - tài chính mới trong nghiên cứu, đánh giá các sự kiện, vấn đề kinh tế của thế giới và Việt Nam. Để phản ánh thực tế của một tiến trình dài lâu, cuốn sách được $\uparrow$ thành ba phần cơ bản. Phần I là các quá trình với những thay đổi có mặt tích cực, có mặt hạn chế, trải dài theo thời gian mà ký ức về chúng vẫn còn mII 
sâu trong nhiều thế hệ công dân. Phần /l đã có những đột phá được chủ kiến đúng và cả sự thúc ép của các điều kiện kinh tế. Những đột phá ấy được xem xét trong cuốn sách như những phạm trù trọn vẹn, là những điểm nhấn làm sáng rõ các hành trình thời gian mà số đông sự kiện có thể che khuất bản chất "đột phá" của những sự kiện có tính chất bước ngoặt, như thay đổi cấu trúc, chuyển hướng tư duy, bứt phá về mô hình. Phần III, các vấn đề kinh tế vi mô và vĩ mô thường không chỉ xuất hiện một lần mà lặp đi lặp lại ở các dạng thức khác nhau, lúc ẩn lúc hiện. Có những vấn đề và bài học mà ích lợi của việc nhận thức, sự đột phá về cơ cấu và tư duy kinh tế không bị bó hẹp trong một khoảng không gian và thời gian cụ thể. Đó còn là những quy luật phổ quát, có xu hướng lặp lại và biến thể mỗi lúc một phức tạp và bất ngờ hơn. Ba phần này tiếp cận nền kinh tế như một chỉnh thể sống trong không gian và thời gian hợp lý, có tính lôgic và những nhận thức có lợi cho tư duy kinh tế lâu dài.

Với sự đầu tư nghiêm túc, lượng thông tin phong phú, được sưu tầm, tuyển chọn và tính toán từ nhiều nguồn trong nước và nước ngoài trong khoảng thời gian dài, cuốn sách cung cấp cho bạn đọc những nét chấm phá lớn trong bức tranh kinh tế Việt Nam từ khi giành được độc lập đến nay.

Để có thêm thông tin chi tiết về những cuốn sách quý, có giá trị, liên quan đến lĩnh vực mình quan tâm, bạn đọc có thể tìm hiểu trên Trang thông tin điện tử của Nhà xuất bản (http://www.nxbctgg.org.vn/) hoặc tại các chi nhánh, trung tâm phát hành, đại lý sách của Nhà xuất bản Chính trị quốc gia Sự thật trên toàn quốc (trực tiếp hoặc qua các trang giới thiệu, bán sách của: Trung tâm Sách Quốc gia, Chi nhánh của Nhà xuất bản tại Thành phố Hồ Chí Minh, Đà Nẵng, Cần Thơ và các Trung tâm phát hành sách tại Huế, Nha Trang, Quảng Ngãi).

NGUYẼN CHÁT

Nhà xuất bản Chính trị quốc gia Sụ̣ thật

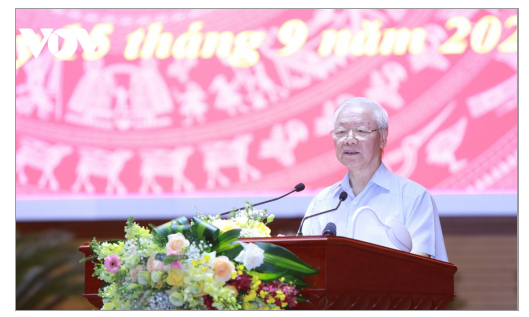

Phát biểu của Tổng Bí thư Nguyê̂̃n Phú Trọng tại Hội nghị toàn quốc các cơ quan nội chính

\section{这 15/09/2021}

CT\&PT - Sáng 15/9/2021, tại Hà Nội, Ban Nội chính Trung ương tổ chức Hội nghị toàn quốc các Cơ quan Nội chính triển khai Nghị quyết Đại hội XIII của Đảng. Tổng Bí thư Nguyễn Phú Trọng tới dự và phát biểu chỉ đạo Hội nghị. Tạp chí Chính trị và Phát triển trân trọng giới thiệu toàn văn bài phát biểu của Tổng Bí thư Nguyễn Phú Trọng:

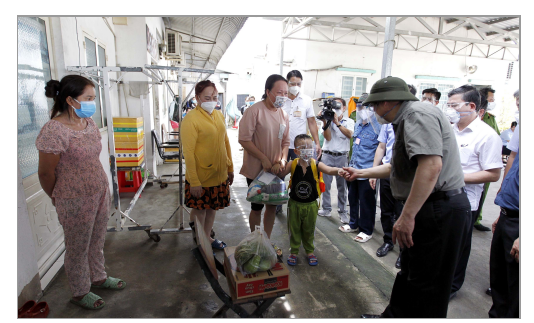

Vận dụng tư tưởng $\underline{\mathrm{H}}$ ồ Chí Minh trong quá trình xây dựng và thực hiện nghị quy ết để "Ý Đảng hợp lòng dân"

通 15/09/2021

CT\&PT - Nghị quyết của Đảng là sự kết tinh tư duy lý luận, được phát triển từ thực tiễn, là ý chí, nguyện vọng của toàn Đảng, toàn dân và toàn quân. Để nghị quyết của Đảng là sự thống nhất "ý Đảng hợp với lòng dân", từng bước thấm sâu vào cuộc sống, thì việc vận dụng tư tưởng Hồ Chí Minh vào quá trình xây dựng và tổ chức thực hiện là việc làm có ý nghĩa hết sức thiết thực; là bài học sâu sắc cho các cấp ủy, chính quyền và toàn xã hội thực hiện thắng lợi các mục tiêu mà nghị quyết của Đảng đã đề ra.

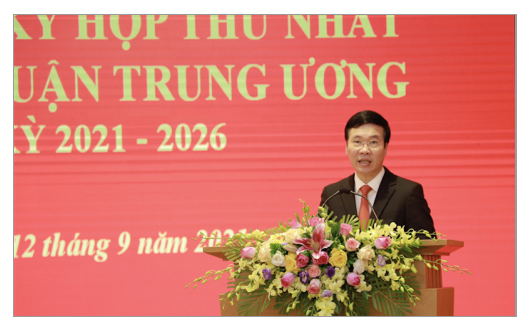

\section{Nâng tầm tư duy lýluận của Đảng}

尚 13/09/2021

Tại Lễ ra mắt và Kỳ họp thứ nhất của Hội đồng Lý luận Trung ương nhiệm kỳ 2021-2026, đồng chí Võ Văn Thưởng, Ủy viên Bộ Chính trị, Thường trực Ban Bí thư có bài phát biểu chỉ đạo việc xây dựng chương trình, kế hoạch triển khai thực hiện trong nhiệm kỳ 2021-2026. Tạp chí Chính trị và Phát triển trân trọng giới thiệu bài viết.

\section{Dưa nghi quy yết cỉa Dảng vào cuộc sống}



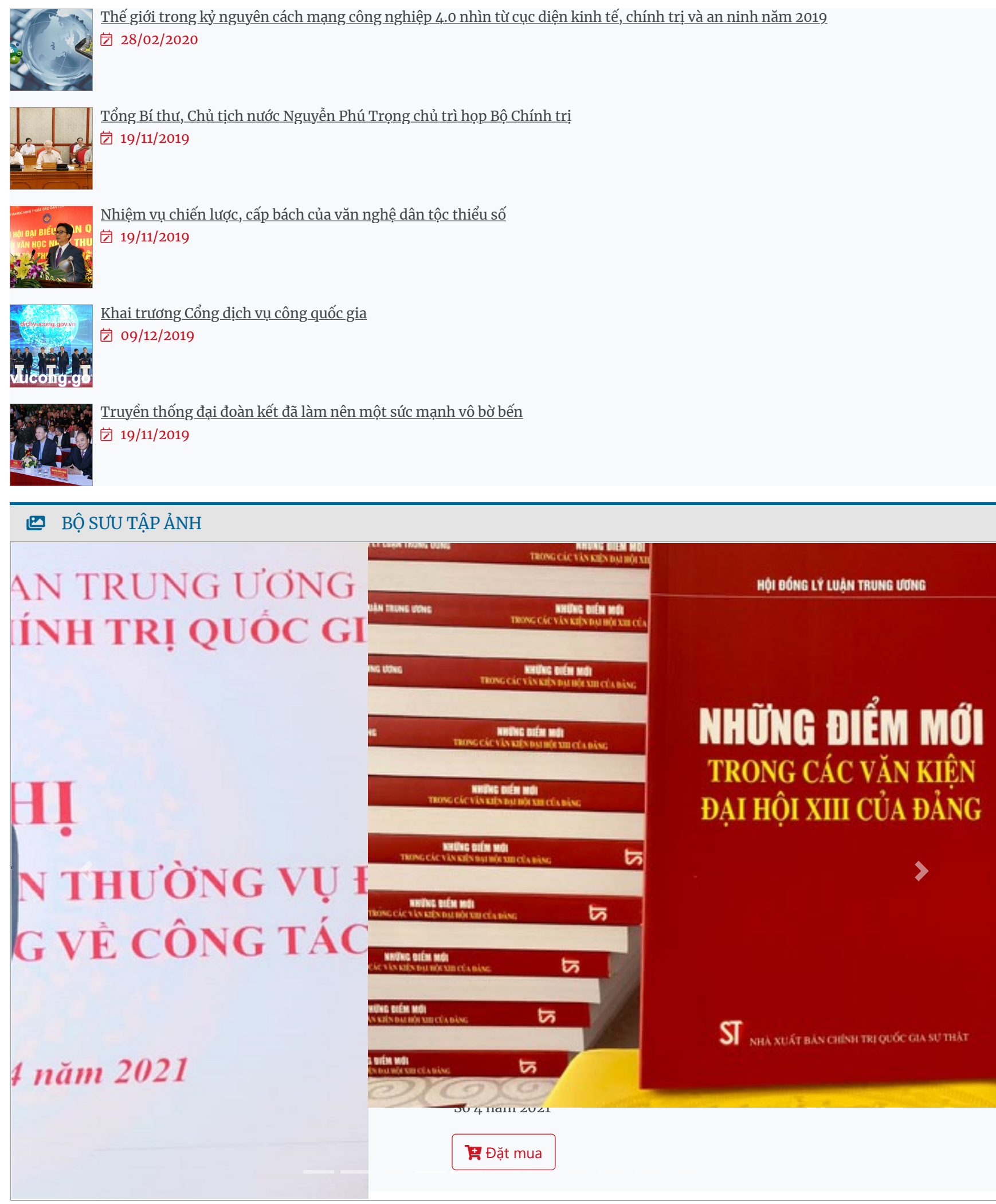

Ç QUYY TRINH GỬI BÀI ONLINE

๑ LIÊN HÊ VÀ ĐÓNG GÓPÝ KIIÉN

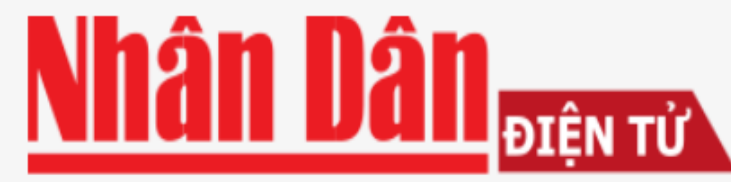

CƠ QUAN TRUNG ƯƠNG CỦA ĐẢNG CONG SẢN VIẸT NAM TIÉNG NÓI CỦA ĐẢNG,NHÄ NƯỚC VẢ NHÂN DÂN VIẸTT NAM 


\section{E \\ tr. Congsain}

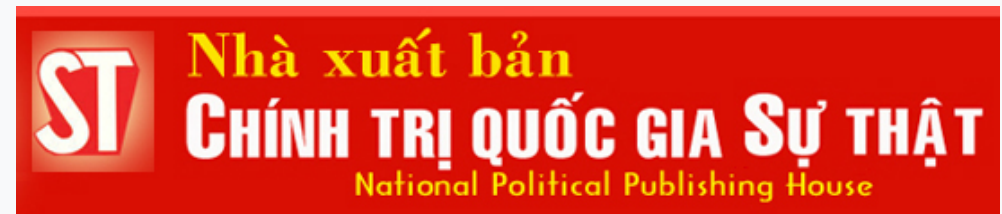

\section{ST masures \\ $\int$ CHíNH TRI QUÓ́C GIA SỰ THẬT}

$\mathcal{S}$ LIÊN KẾT

Nhà xuất bản Chính trị Quốc gia Sự thật

Hệt thống phân phối sách điện tử

จ LIÊN HÊQQUẢNG CÁO

(C) Chính trị và Phát triển

Tạp chí nghiên cứu của Nhà xuất bản Chính trị quốc gia Sự thậ $t$

Giấy phép hoạt động báo điện tử số: 458/GP-BTTTT, ngày 20/7/2021 của Bộ Thông tin và Truyền thông Tổng Biên tập: TS. Hoàng Mạnh Thắng

Vui lòng dẫn nguồn "chinhtrivaphattrien.vn " khi bạn phát hành lại thông tin từ website này.

Điện thoại: 0243.822.1638 | Fax: 08.049222 


\section{Tài liệu tham khảo:}

[1] Nguyễn Phú Trọng. (2021). Tầm nhìn chiến lược và ý chí vươn lên của dân tộc. Nxb Chính trị Quốc gia Sự thật, Hà Nội.

[2] Ban Tuyên giáo Trung ương Đảng. (2021). Tổng tập chuyên đề Học tập và làm theo tư tưởng, đạo đức, phong cách Hồ Chí Minh. Nxb Chính trị Quốc gia Sự thật, Hà Nội.

[3] Ban Tuyên giáo Trung ương Đảng. (2021). Học tập và làm theo tư tưởng, đạo đức, phong cách Hồ Chí Minh: Hiện thực hóa khát vọng phát triển Việt Nam phồn vinh, hạnh phúc. Nxb Chính trị Quốc gia Sự thật, Hà Nội.

[4] Ban chấp hành Trung ương Đảng. (2021). Văn kiện Đại hội đại biểu toàn quốc lần thứ XIII. Nxb Chính trị Quốc gia Sự thật, Hà Nội.

[5] Trịnh Nhu. (2021). Lịch sử Đảng Cộng sản Việt Nam. Nxb Chính trị Quốc gia Sự thật, Hà Nội.

[6] Nguyễn Viết Thông. (2021). Hỏi - đáp về kết quả 10 năm thực hiện Cương lĩnh xây dựng đất nước trong thời kỳ quá độ lên chủ nghĩa xã hội. Nxb Chính trị Quốc gia Sự thật, Hà Nội.

[7] Nguyễn Chu Hồi. (2020). Kinh tế biển xanh: Các vấn đề và cách tiếp cận cho Việt Nam. Nxb Chính trị Quốc gia Sự thật, Hà Nội.

[8] Nguyễn Xuân Thắng. (2021). Tư tưởng, lý luận với đổi mới và phát triển đất nước. Nxb Chính trị Quốc gia Sự thật, Hà Nội.

[9] Phạm Minh Chính, Vương Quân Hoàng. (2021). Kinh tế Việt Nam: Thăng trầm và Đột phá. Nxb Chính trị Quốc gia Sự thật, Hà Nội. 